\title{
Optical Limiting of Gold Nanoparticle Aggregates Induced by Electrolytes
}

\author{
Gang Wang, Wenfang Sun*
}

Department of Chemistry and Molecular Biology, North Dakota State University, Fargo, ND 58105

${ }^{*}$ Corresponding author. Phone: 701-231-6254; Fax: 701-231-8831; E-mail: Wenfang.Sun@ndsu.edu 


\section{Experimental Section}

Citrate-capped gold nanoparticle colloids with nominal size of $10 \mathrm{~nm}$ were purchased from Sigma. $\mathrm{KCl}$ was obtained from Alfa Aesar and was dissolved in distilled water to prepare a concentrated solution of $5.0 \mathrm{~mol} / \mathrm{L}$. $40 \mu \mathrm{L}$ of the concentrated $\mathrm{KCl}$ aqueous solution was added to $0.4 \mathrm{~mL}$ of gold nanoparticle colloid. One drop of freshly prepared aggregates before and after optical limiting experiment was placed on 300 mesh Formvar coated grids using an eppendorf micropipette and immediately wicked off using filter paper. After allowing the sample to dry, images were obtained using a JEOL 100CX II Transmission Electron Microscope at $80 \mathrm{KeV}$. 


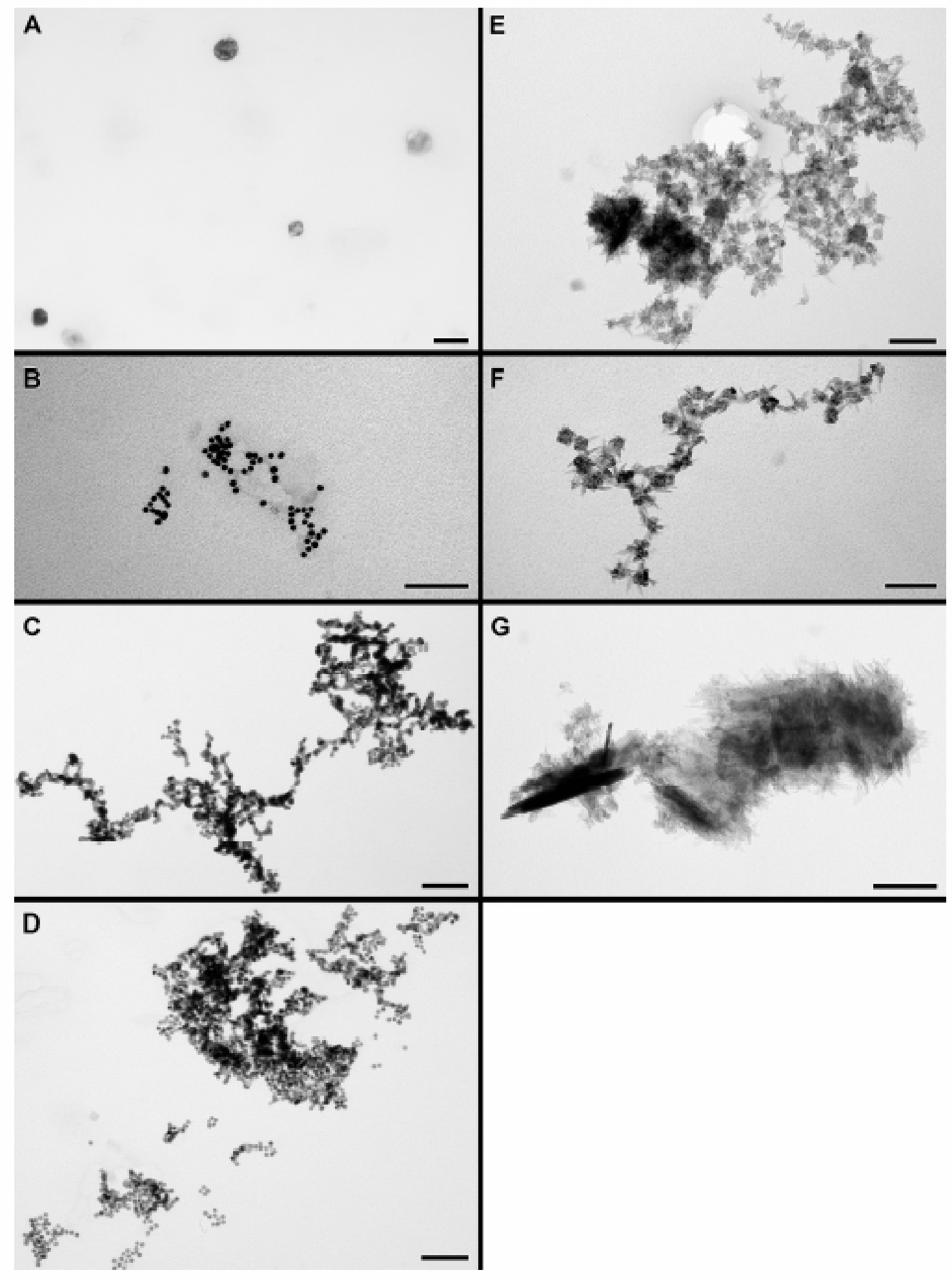

Figure S1. TEM images of aggregated $10 \mathrm{~nm}$ gold nanoparticles at $0.50 \mathrm{M} \mathrm{KCl}$ before (A-D) and after (E-G) optical limiting experiment. The scale bar represents $100 \mathrm{~nm}$. 